\title{
Uganda's Fiscal Policy (2000-2016): Implications for Public Investment Management (PIM)
}

\author{
Asumani Guloba \\ Policy Research, National Planning Authority, Kampala, Uganda \\ Email: aguloba@npa.ug, aguloba@gmail.com
}

How to cite this paper: Guloba, A. (2018) Uganda's Fiscal Policy (2000-2016): Implications for Public Investment Management (PIM). American Journal of Industrial and Business Management, 8, 514-536. https://doi.org/10.4236/ajibm.2018.83034

Received: February 5, 2018

Accepted: March 11, 2018

Published: March 14, 2018

Copyright $\odot 2018$ by author and Scientific Research Publishing Inc. This work is licensed under the Creative Commons Attribution International License (CC BY 4.0).

http://creativecommons.org/licenses/by/4.0/

\section{(c) (i) Open Access}

\begin{abstract}
Uganda has recently pursued expansionary fiscal policies, driven by the desire to improve the country's infrastructure, increase the production of assets, and facilitate accelerated growth. Nevertheless, providing more resources for capital development in line with the country development aspirations alone will not necessarily translate in optimal infrastructure investments. A question that arises is, what comes first: Is it to invest in the effort to establish effective systems for managing public investment in order to yield high returns or should financing these investments precede capacity challenges. Using a rich dataset of public sector projects defined by project, financing mix, sector etc; the paper carries out project absorptive capacity and overall fiscal trend analysis to ascertain whether budgeted projects translated to intended outturns. It is found that weak Public Investment capacity has led to less than budgeted public investment outturn which has reduced intended fiscal policy impact. As such, for Uganda to achieve its fiscal objectives there is need to balance its expansionary fiscal policies with the ability to absorb fiscal resources.
\end{abstract}

\section{Keywords}

Fiscal Policy, Public Expenditure, Public Investment

\section{Introduction}

There is a high-profile debate in many countries about the role of the state in managing economic development. The ideological preferences of the citizens and political leaders have an important influence on where the balance lies between a dominant role and a facilitative and limited role. Apart from the extreme libertarian view, however, there is a common acknowledgment that gov- 
ernment has a role in undertaking public investments that private enterprise alone would not provide because of the fundamental incentive problems due to non-appropriability and non-exclusion that are characteristic of public goods [1].

The idea that governments ought to invest in public infrastructure and institutional assets to support production and trade is well established in the economic literature going back at least to Adam Smith [2]. Gaps in infrastructure stock undermine economic outcomes and growth among many developing countries and particularly in Africa [3]. Governments all over the world undertake public investments with the aim of satisfying societal needs while improving the overall welfare of their citizens [1]. Increased infrastructure investment can lead to faster economic growth. Infrastructure permits larger interchange and reduces effective distances, thereby facilitating trade and agglomeration [4]. As a result, the benefits to society almost certainly exceed the sum of all the private benefits. Moreover, in a world where private capital, private companies and ideas are increasingly mobile, a nation's infrastructure is "distinctively local and distinctively defining of its strength" [4]. Such investments could include roads, railways, hospitals, schools, market places, bridges and dams among others [1].

Although Uganda has made progress in infrastructure development the country still faces huge deficits across all sectors including in the transport, energy, water and information technology that require financing beyond available public budget ceilings [5]. These deficits in infrastructural provision affect the business climate and increase the cost of doing business with implications for enterprise growth and job creation [6]. In addition, infrastructural deficits exacerbate poverty and inequality [7].

Accelerating Uganda's structural transformation and transition towards middle income status will require facilitating higher levels of growth, improving productivity, and creating jobs for the large and growing population. A key strategy that Government has pursued over the past seven years has accordingly been to adjust the fiscal policy to provide more resources for capital development in line with the National Development Plans (NDPs). This strategy is expected to be continued into the medium term in order to address the binding constraints on growth, most notably the country's huge infrastructure deficit. The intention to increase the level of capital investment is further driven by the prospect of revenues from the exploitation of oil, which creates new opportunities to finance the development of critical infrastructure and human capital investments [3].

The fiscal strategy of the NDPII is underpinned by the need to maintain macroeconomic stability and a quest to competitively position Uganda to fully benefit from the East African Common Market. For this to be realized, it will require addressing the key binding constraints to growth and factors that can reduce the costs of doing business in Uganda. The focus of addressing the infrastructure deficit while consolidating the gains in human capital development is a key priority for the NDPII. As such, the fiscal deficit will be mainly driven by the 
additional resources required for infrastructure and human capital development [8].

Therefore, Uganda has recently pursued expansionary fiscal policies, driven by the desire to improve the country's infrastructure, increase the production of assets, and facilitate accelerated growth and productive exploitation of oil resources. But challenges related to budget execution could prevent Uganda from achieving its objective of accelerating growth in the short-term and raising productivity to be able to sustain a high rate of growth of its economy in the medium to long term [3]. Providing more resources for capital development in line with the NDPs alone will not necessarily translate in optimal infrastructure investments. That is, the availability of financing alone does not directly translate in optimal infrastructure investments. Availability of resources is a crucial step to ensuring investments in public infrastructure, however, absorption of these resources and efficient utilization are important in ensuring that resources actually translate into optimal investments and thus provide optimal economic returns. Indeed, the return on public infrastructure investment will depend on several factors which include: cost of financing, efficient implementation, efficient absorption of financing, institutions and prudent maintenance of infrastructure investment [9].

The challenge then is to ensure that where public investments are required, they be undertaken with regard to efficiency and value for money, among other reasons to minimize the need for taxation, which may impose a distortionary impact on citizens, or the need for borrowing, which may impose a burden on future citizens [1]. Naturally a question that arises is, what comes first: Is it to invest in the effort to establish effective systems for managing public investment in order to yield high returns or should financing these investments precede capacity challenges.

This paper analyzes Uganda's fiscal policy between 2000 and 2016 to ascertain whether it is consistent with government intended objectives. Specifically, the paper examines whether Uganda's fiscal strategy of availing resources for infrastructure investments indeed translated into planned expenditure on public investments. The main question assessed is whether government was able to prudently absorb available resources to execute public investments. Low absorption capacity implies that it is not question of inadequate funds rather the inability to utilize the available funds. Therefore, the paper goes further to ascertain Uganda's actual fiscal policy implications for public investment management in Uganda. In so doing, the paper contributes to the debate of what precedes what; It is investment financing or capacity to invest in order to provide optimal capital investments [1]. Using a rich dataset of public sector projects defined by project, financing mix, sector etc; the paper carries out project absorptive capacity and overall fiscal trend analysis to ascertain whether budgeted projects translated to intended outturns. It is found that weak Public Investment capacity has led to less than budgeted public investment outturn which has reduced intended fiscal policy impact. As such, for Uganda to achieve its fiscal objectives there is 
need to balance its expansionary fiscal policies with the ability to absorb fiscal resources.

The rest of the paper is structured as follows: Section 2 provides the literature; Section 3 presents methodology; Section 4 analyzes Uganda's fiscal policy between 2000 and 2016; Section 5 assesses the absorption of public expenditure whether they are in line with the fiscal strategy; Section 6 discusses the findings and Section 7 concludes.

\section{Literature}

The literature presented in this paper draws on a detailed discussion on the topic in The Power of Public Investment Management [1].

The idea that governments ought to invest in public infrastructure and institutional assets to support production and trade is well established in the economic literature going back at least to Adam Smith [2]. Underlying Smith's vision was the idea that government provision of complementary public goods such as roads and bridges would facilitate the development and growth of markets and long-term economic growth. Private enterprise by itself would be unlikely to provide such public works, and that implicit market failure, without government provision, would constrain economic growth.

John Maynard Keynes [10] provided a complementary rationale for public investment as a tool of countercyclical fiscal policy, justifying public works programs during the Great Depression as a means to stimulate aggregate demand, catalyze the income and employment multiplier, and thereby restore the economy to full employment. Ever since Keynes, governments have sought to justify deficit-financed public investment projects as a corrective response, both to serve as a countercyclical stimulus and to enhance the stock of public assets that could support private sector enterprise and long-term economic growth.

The models of economic growth that motivated five-year plans and industrialization strategies in much of the developing world in the postwar years were heavily dependent on high levels of public investment and estimates of aggregate and sectoral growth based on capital output ratios [3]. Countries invested not only in basic infrastructure for agricultural and industrial development (dams, irrigation canals, power grids, roads, and ports) but also, in some cases, in directly productive activities as state-owned enterprises grew and expanded into sectors where there was no justification (based on principles of public economics) for that role.

Public infrastructure has typically been the preferred form of fiscal investment given its justification as a public good with its broadly distributed benefits to the population. But the size and sign of the productivity of public investment is an empirical question that has stimulated a considerable literature, starting with the paper on Public Investment, the Rate of Return, and Optimal Fiscal Policy by [11]. [12] showed that the stock of nonmilitary public infrastructure (such as roads, highways, airports, mass transit, and water and sewer systems) was a sig- 
nificant determinant of national income productivity in the United States and that the decline in productivity in the 1970s and 1980s could be attributed to the low rate of public investment. Subsequent work by [13], using endogenous growth models and including the effect of public spending on education, noted that estimates of the productivity effects of infrastructure were probably more modest than suggested by Aschauer but that a positive effect is generally expected. [14] indicates that every dollar of investment in the interstate highway network during 1954-2001 in the United States contributed to six dollars of economic productivity.

The interest in public investment took a new and interesting turn in the early years of this century when a number of developing-country governments, particularly in South America, began to complain about the restrictions imposed on their capacity to undertake public investments by the macroeconomic stabilization framework recommended by the International Monetary Fund (IMF). In effect, governments facing macroeconomic pressures that tended to increase indebtedness and inflation were advised to follow restrictive fiscal policies that reduced government spending and borrowing. In many cases, these fiscal adjustments were achieved by cutting back on discretionary spending, with public investments typically bearing the brunt of such cutbacks. However, after a few years of politically difficult fiscal restraint, governments expressed concern that an exclusive focus on macroeconomic stabilization was shortsighted and that decisions to curb public investments for a prolonged period would result in sacrificing the potential for long-term growth.

Many developing countries face tremendous deficits in terms of provision of economic and social infrastructure, and the government is expected to be a principal actor in closing these deficits through public policy. Fiscal policies that were defined by a focus on the fiscal deficit alone did not acknowledge that the opportunity cost of delayed development may be detrimental even to fiscal stability.

[15] reviewed the evidence of fiscal adjustments undertaken by a number of countries through the 1990s and concluded that the cutback in public investment had in fact contributed to a decline in economic growth and that, from an intertemporal perspective, this may have been a suboptimal design of fiscal policy. Rather than promoting fiscal sustainability, cutting public investment may lead to a weakening growth process with adverse, rather than positive, consequences for fiscal solvency. A better approach would be to adopt a longer-term perspective to the design of fiscal policy with a view to maximizing government net worth. Taking into account the evidence that the quality (speed and composition) of fiscal adjustment during an episode of macroeconomic stabilization has significant implications for growth, the World Bank (2016) proposed ways in which fiscal policy might be designed to promote growth and development while preserving macroeconomic stability. Some general principles should apply: cuts in public consumption are preferable to cuts in public investment, and a reallo- 
cation of resources from lower-efficiency uses to more productive uses is likely to be more long-term growth enhancing, other things being equal, than raising additional revenue or borrowing to finance the same productive expenditure.

But these principles should be combined with an understanding of the specific country circumstances to customize fiscal policy design. The amount of "fiscal space" to finance new public investment would depend on the individual country context and whether there was room to reallocate resources to investment by improving the efficiency of public spending. Where the room to improve efficiency is limited, countries may seek to undertake investments through accessing external aid or implementing additional revenue measures.

Much of the argument for public investment relies on the belief that resources allocated to investment translate into an equivalent value of public capital stock, which, by lowering the cost of production or distribution, benefits the private sector and affects the overall growth process. This effect is typically measured by the rate of economic or social return from public investment. Social cost-benefit analysis is intended to define the expected rate of return on an investment, taking account of likely costs and benefits including any economic and social externalities.

But this rate of return will depend very much on the effectiveness of the management of the public investments, both in the budgeting and execution of the investment projects and in the subsequent operation and maintenance of the public asset created by public investment. Typically cost-benefit analysis assumes a frictionless process of project implementation. However, if the quality of public investment management (PIM) is low, and if resources are wasted or corruptly misdirected, it is likely that the realized (or ex post) rate of return will be low or negative even for projects that showed ex ante high rates of return. Without efficient management of public investments, investment spending is unlikely to be fiscally sustainable and would not promote growth and development.

It is against this background that this paper examines whether Uganda's fiscal strategy of availing resources for infrastructure investments indeed translated into planned expenditure on capital investments. The main question assessed is whether government was able to prudently absorb available resources to execute public investments. Low absorption capacity implies that it is not question of inadequate funds rather the inability to utilize the available funds.

\section{Methodology}

\subsection{Methodological Approach}

The analysis in this paper followed two complementary approaches to analyze Uganda's fiscal policy and its implications for PIM. The first approach involved a critical review of existing literature and documents on Uganda's fiscal policy and strategies. These documents included the National Development Plans, Budget Documents, and IMF fiscal review mission findings. The second ap- 
proach involved a quantitative analysis of relevant data for fiscal policy and public investments in Uganda.

Annual historical fiscal data from 2000 to 2016 is used for the analysis of Uganda's fiscal policy to draw out fiscal policy objectives both planned and actual. A de-compositional and trend analysis at specific fiscal variables is carried out. This is done at all levels of fiscal aggregation to include expenditures, revenues and financing. Where possible a comparable analysis is carried to compare Uganda's fiscal policy with that of its neighboring countries. The analysis is useful in ascertaining fiscal priorities, implementation and its implications for public investment management.

For the Public Investment Absorption Performance analysis a rich detailed Public Investment Plan database from FY1995/96 to FY2015/16 was compiled. The database is defined by: specific projects, financing type (Government or Type of Donor), sector, budget and actual expenditure. Using excel analytical tools this data is grouped and analyzed at different sector levels and financing type.

\subsection{Data Sources}

Annual historical fiscal data was collected from official Ministry of Finance and Planning (MoFPED) and complemented by International Monetary Fund (IMF) and World Bank sources. The PIP database was collected from MoFPED Treasury sources for donor financing component and MoFPED Budget office for Government of Uganda (GoU) financing component. This is a rich excel dataset of public sector projects since 1997/98 defined by project name, financing type, sector, expected duration and time since implementation. However, since 2013, this data is kept in separate databases based on the financing type. The treasury department database comprises the donor component project, while Budget Office of MoFPED database has the Government of Uganda financing of the same project. As such, to get a complete picture on the total financing of projects by name, a matching exercise was carried out to match the two datasets into one complete database. This data was complemented with MoFPED BOOST budget database that spans from FY2003/04 to date. The BOOST database in a detailed national budget database that comprises that national budget time series data defined by budget item, economic classifications, administrative allocations and rate of budget executions. Analysis of these data is quite involving, it requires careful data matching using excel commands and deriving analytical tables and figures.

\section{Analysis of Uganda's Fiscal Policy between 2000 and 2016}

Recent fiscal policy is expansionary to unprecedented levels. From 2000 to date, three phases are visible in Uganda's fiscal policy; the 2001-2003 fiscal expansion, 2004-2008 fiscal consolidation, the 2009-2016 fiscal expansion (Figure 1). Uganda is currently in an expansionary phase of its fiscal policy reflected in a 
widening primary deficit. This current fiscal expansion continues from a fiscal stimulus implemented in 2009-2011 to counter the effects of the global economic crisis. However, despite a slight decline in the expansionary stance in 2012/13 there has been a significant fiscal expansion over the last four years, 2012/13 to 2015/16. This fiscal expansion has seen aggregate spending increasing by an average 1.8 percent of GDP over the four years. Except for 2015/16, this expansion has mainly been achieved through domestic borrowing which has increased the primary deficits in excess of 2.7 percent of GDP.

Public Investment spending is driving the recent fiscal expansion. The gap between recurrent and development spending is declining (Figure 2). Recurrent expenditure as a share of the total spending declined from 64.6 percent of the total spending in 2004-08 period to 58 percent in 2009-15. On the other hand, development expenditure share of the total spending rose from 35.4 to 42 in the

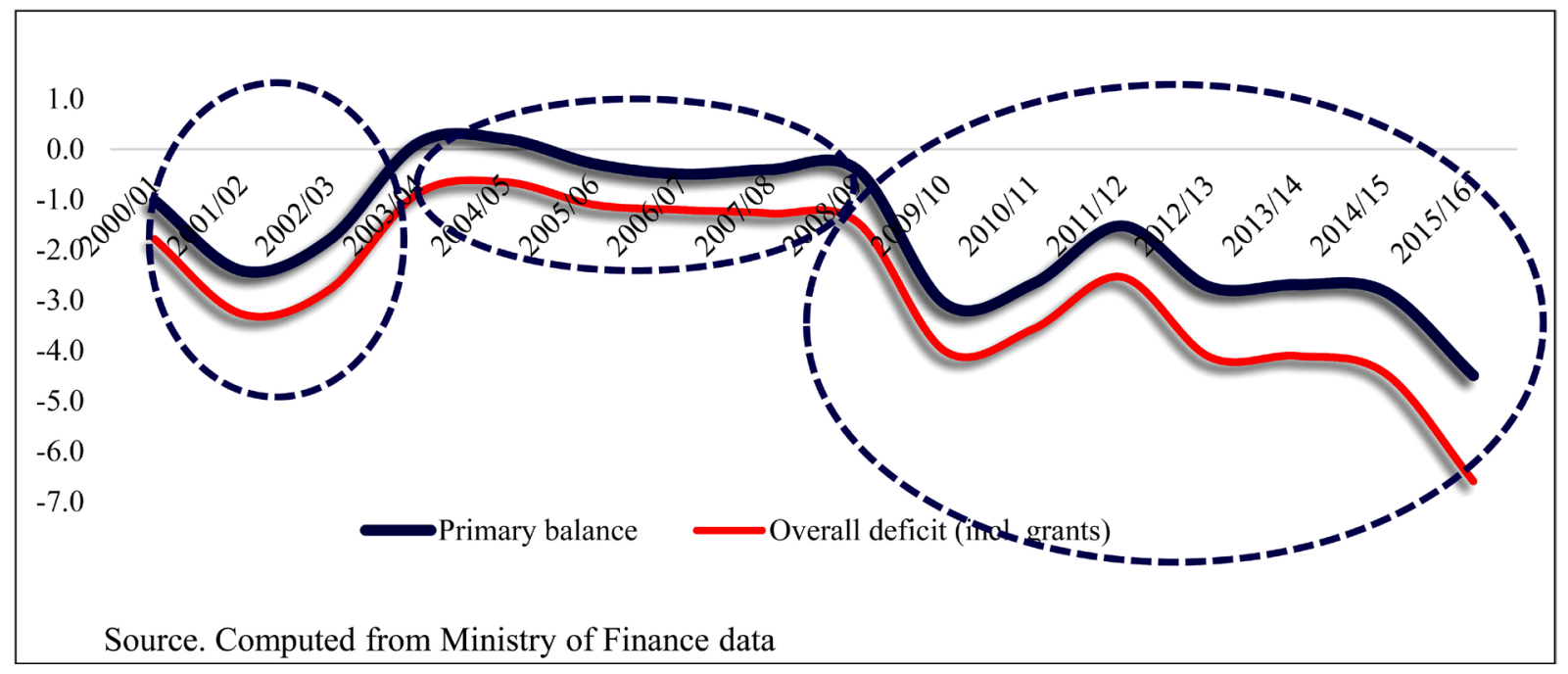

Figure 1. Uganda: Fiscal stance (2000/01-2015/16), in percent of GDP.

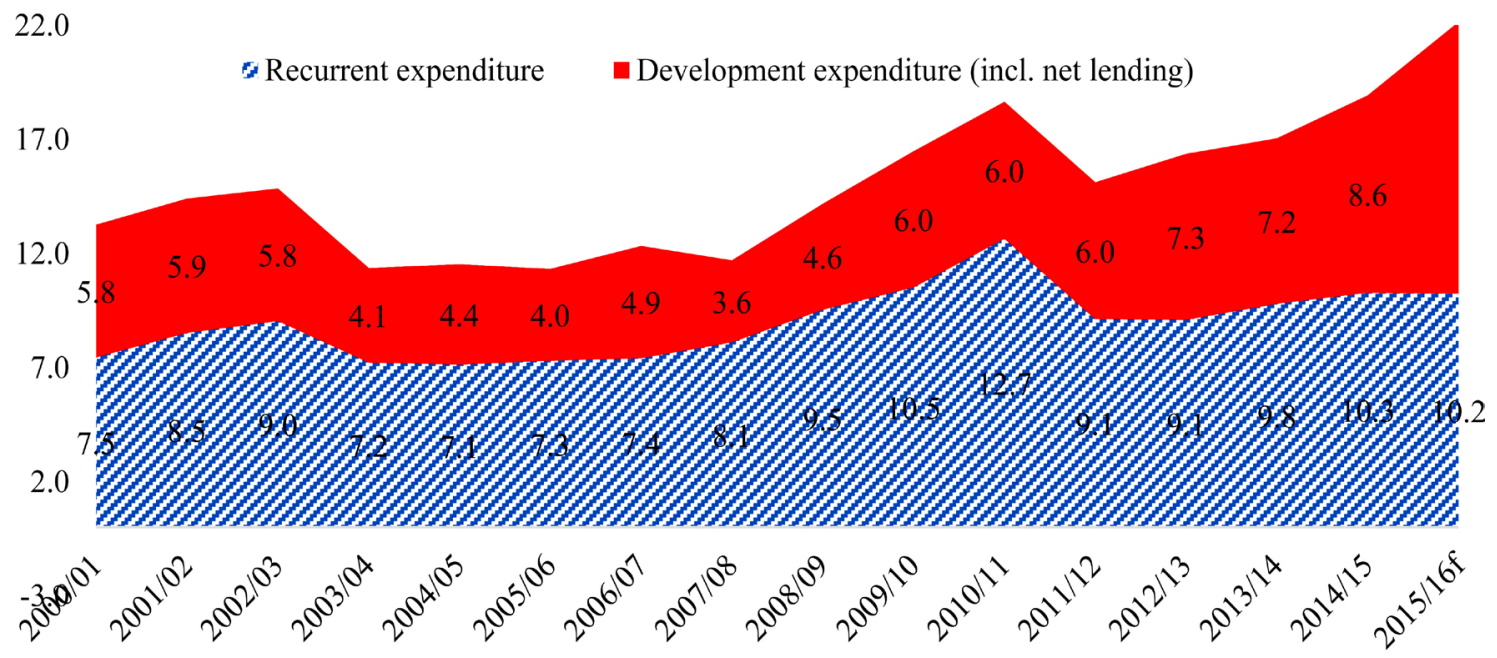

Source. Computed from Ministry of Finance data

Figure 2. Expenditure Trend, in percent of GDP. 
corresponding period, demonstrating government's continued efforts towards infrastructure investments. Recurrent expenditure has increased from 7.9 percent of GDP to 10.2 percent in the corresponding period. Nevertheless, development expenditure grew more from 4.3 percent of GDP to 7.6 in the corresponding period with a significant ramp up averaging 8.8 percent of GDP in the past four years.

Wages which are the main driving factor of recurrent expenditures in most countries have largely remained unchanged at about 3.4 percent of GDP since 2004. This compare favorably with Uganda's peers whose public sector wage bill averages above 7 percent of GDP.

Ex ante spending priorities are aligned with development plans. The composition of expenditure reflects government's own priorities. Uganda's development objectives are stipulated in the government's Vision 2030 and the medium term priorities as stipulated in the NDPI \& II. The government aims at enhancing both the scale and pace of economic transformation through strengthening Uganda's competitiveness for sustainable wealth creation, employment and inclusive growth. In this regard, Agriculture, Tourism and Minerals sector are identified as the priority productive sectors with infrastructure development and human capital development as the fundamental opportunities unlocking sectors.

Infrastructure sectors (Works and Transport and Energy sectors combined) take the largest share of total budget and this share has significantly increased in the last seven years. Works and Transport sector takes the largest budget and this share has increased from an average of 1.9 percent of GDP in 2004/05-2008/09 period to 3 percent in the past seven five years (Figure 3). Also, the energy and mineral sector's which prior to the last seven years was lagging behind Education, Health, Public Sector Management, and Security sectors, has risen in

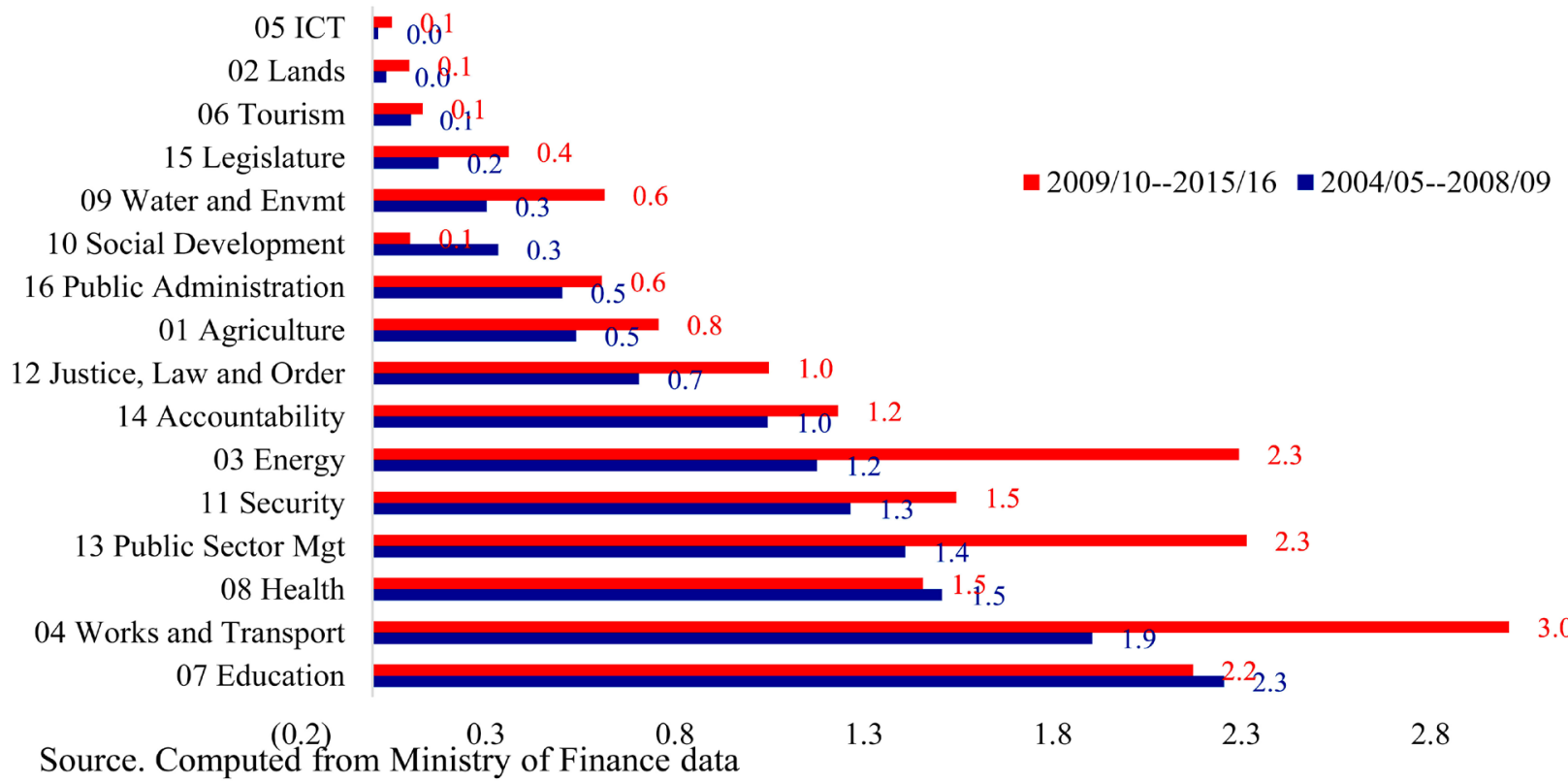

Figure 3. Approved Sector Spending (2006-16), in percent of GDP. 
importance to second place in budget allocation after Works and Transport sector. The Energy and Minerals sector budget share rose from an average of 1.2 percent of GDP in 2004/05-2008/09 period to 2.3 percent in the last seven years. This infrastructure spending is mainly directed to flagship projects identified by the NDPs.

Education sector dominates the social sector budget allocations. After infrastructure and public sector management sectors, education sector takes a large share of the budget. Nevertheless, the sector allocation has somewhat remained unchanged at about 2.3 percent of GDP since FY2004/05 and its importance has been surpassed by Energy sector and is now similar to Public Sector Management sector (Figure 3). Education sector budget is largely recurrent in nature and mainly for staff wages and emoluments.

Government budget is largely implemented at the Centre, implying PIM is largely a Central Government Development challenge (Figure 4). Despite a high proliferation of districts, the budget (less interest payments) executed at local government is shrinking. The budget share to local governments (LG) has shrunk from 24 percent in FY2003/04 to a current low of 14 percent in FY2015/16 (Figure 4). On the other hand, the budget share to central government (CG) has increased from 76 percent to 86 percent. Furthermore, the budget executed at LGs is largely recurrent in nature as the development function is largely a CG issue. The LGs development budget has shrank from a peak of 30 percent of the LG budget allocation in FY2009/10 to 14.2 percent in FY2015/16. As such, since only a small portion of the national public investments budget is executed at LGs, the public investment management (PIM) challenge is largely a CG issue.

Uganda's Budget Expenses are the lowest within EAC comparator countries but they are catching up as Public Investment projects are frontloaded in anticipation of EAC convergence criteria. Uganda's central government expenditure

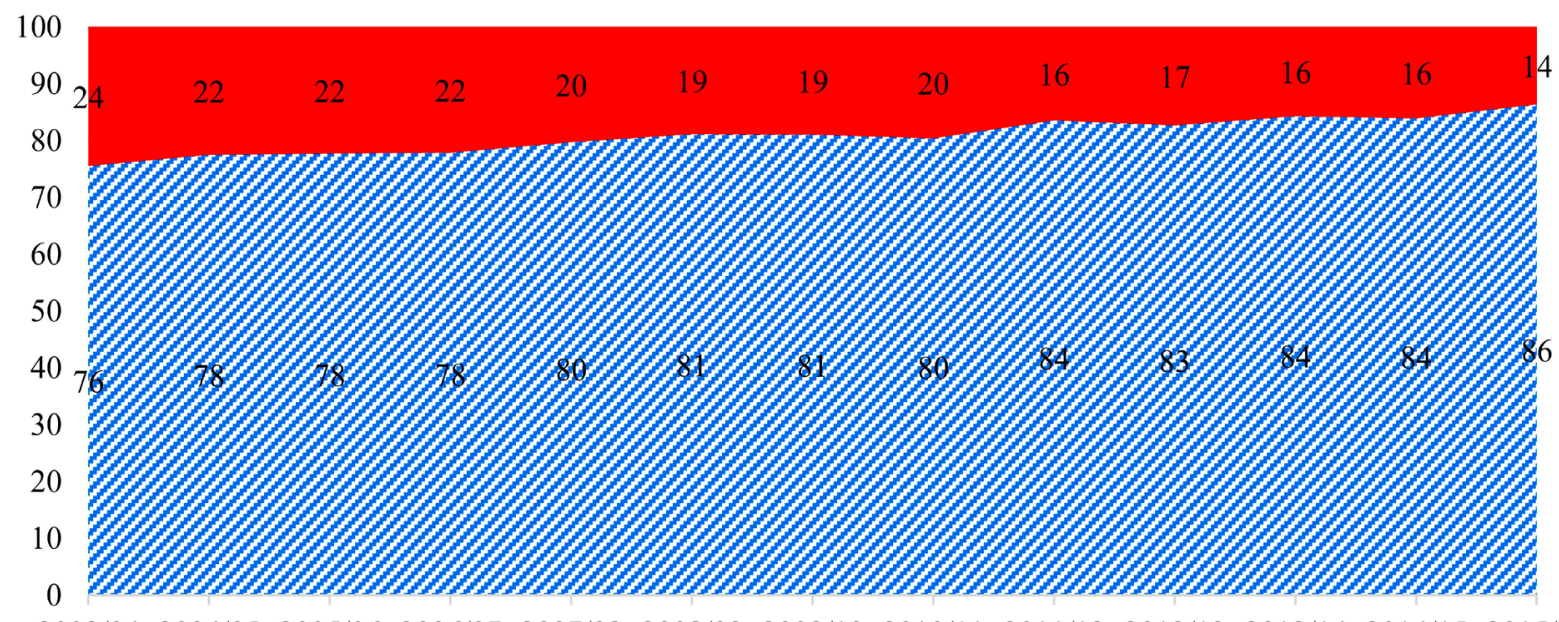

2003/04 2004/05 2005/06 2006/07 2007/08 2008/09 2009/10 2010/11 2011/12 2012/13 2013/14 2014/15 2015/16

Source. Computed from Ministry of Finance data

01 Central Government $\quad 02$ Local Government

Figure 4. Budget Allocation (less interest payments) between Central and Local Government (2003/04-2015/16). 
35.0

30.0

25.0

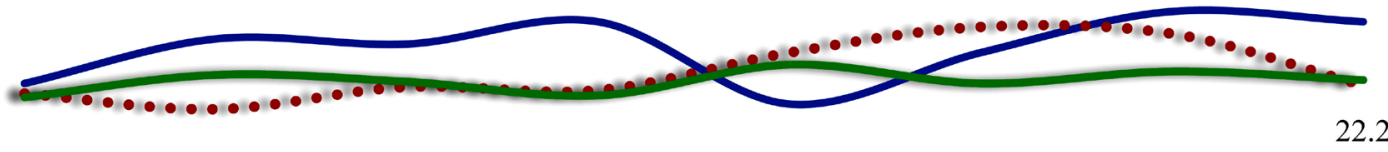

20.0

15.0 15.0

10.0
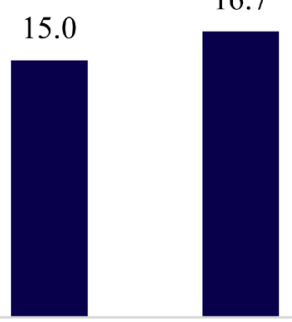

19.1
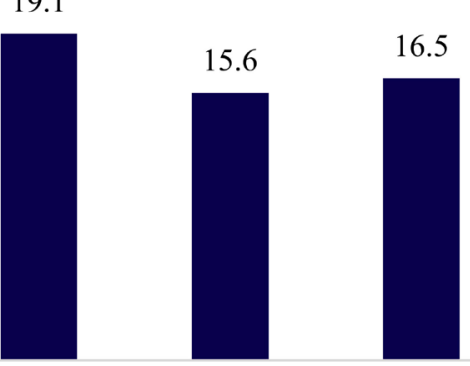

16.7

19.4
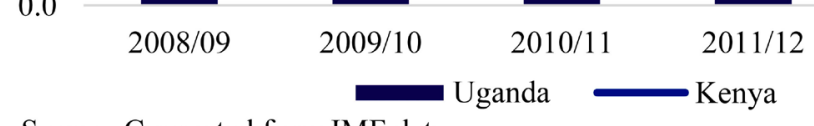

2012/13

Kenya

Source. Computed from IMF data

Figure 5. Government expenditures in EAC States, percent of GDP.

as a percent of GDP lags behind that of Kenya, Rwanda and Tanzania. Over the period FY2008/09 to FY2015/16, the fiscal expenditure of Kenya, Rwanda and Tanzania have evolved together averaging 29, 28 and 27 percent of GDP respectively. In comparison, Uganda's fiscal expenditure has been much lower averaging 17.4 percent of GDP in the corresponding period (Figure 5). Nevertheless, Uganda's fiscal expenditure is catching up to that of its peers. For instance, while Kenya's fiscal spending was 11.9 percentage points of GDP higher than that of Uganda in FY2008/09, in FY2015/16 this gap has narrowed to 8.3 pp. Similarly, the gap has narrowed in comparison to Tanzania and Rwanda. Uganda's increasing expenditures have been largely driven by the front loading of public investments in anticipation of EAC convergence criteria which will cap the fiscal stance.

The fiscal policy is becoming more expansionary and in 2015/16 budget it outpaced EAC comparator states. After Rwanda, Uganda's fiscal deficit averaging 3.4 percent of GDP (in 2008/06-2014/15 period) was second lowest in the EAC region (Figure 6). At 5.3 percent of GDP in the corresponding period, Kenya and Tanzania had higher fiscal deficits. Nevertheless, at a projected 6.6 percent of GDP in 2015/16 budget, Uganda's fiscal stance has been expansionary only second to Tanzania (at 6.9 percent). This expansionary fiscal stance is consistent with ramped up public investments that are expected to bridge the infrastructure deficit in roads and hydroelectricity projects.

The rising fiscal deficits have been driven by expenditure growth that has outpaced revenue growth, revenue growth has largely been stagnant. In the 2012-16 period revenue averaged 12.4 percent of GDP, an improvement over 10.5 registered over the 2007-11 period. This improvement is however lower than expenditure growth which averaged 17.9 percent of GDP in 2012-16 period, an increase from 14.7 in $2007-11$ period (Figure 7). Further, grants declined by 


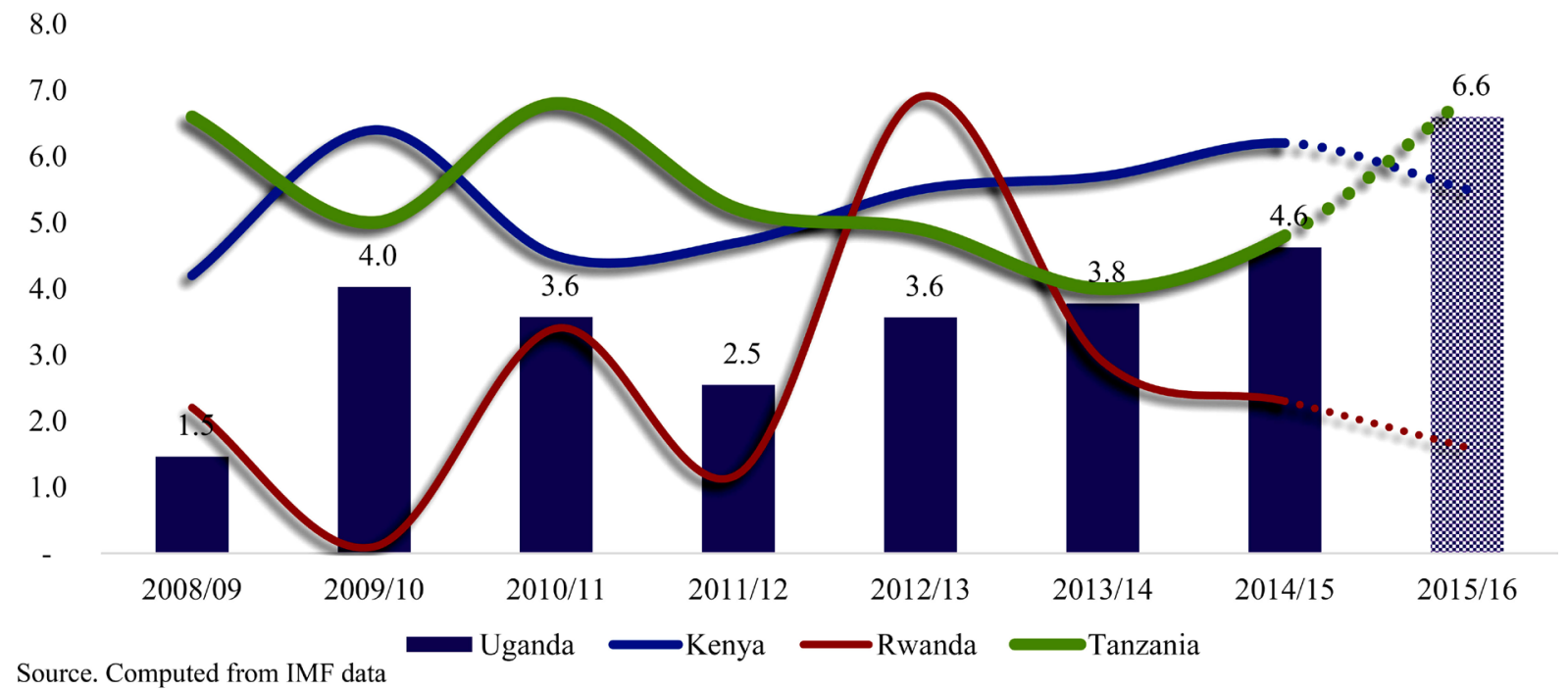

Figure 6. Fiscal Deficit (incl. grants) in EAC states, in percent of GDP.

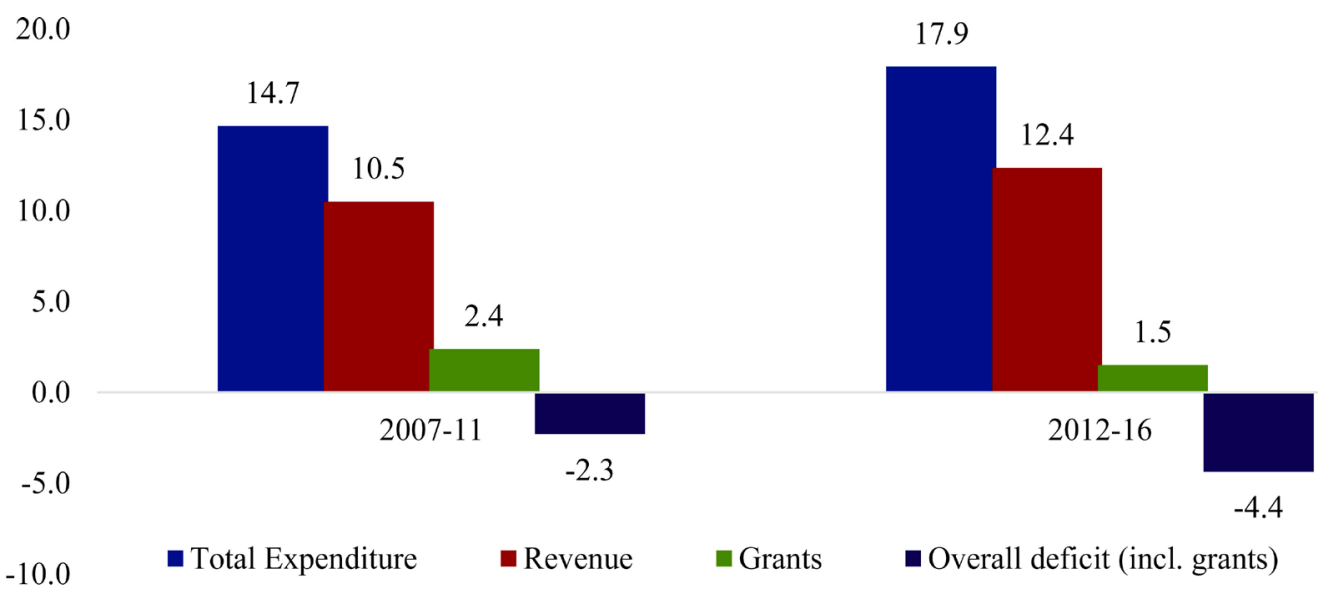

Source. Computed from Ministry of Finance data

Figure 7. Total Budget, in percent of GDP.

0.9 percentage points. As such, fiscal deficit (including grants) worsened from 2.3 percent of GDP (2007-11) to 4.4 percent of GDP (2012-16).

The deficit was financed through a combination of domestic and external borrowing. However, except for 2015/16, domestic borrowing has become important in recent years, as external financing has remained largely unchanged averaging 1.7 percent of GDP in the last four years preceding 2015/16. In $2015 / 16$, the mix of external financing has significantly changed as at 4.1 percent of GDP non-concessional borrowing is expected to finance a larger component of the deficit (Figure 8).

Uganda's tax yield is lowest in the EAC region and will have implications for fiscal objectives under EAC convergence criteria. Uganda's Tax revenue yield is a source of concern that will constrain achieving expenditure priorities set out in the NDP and more so when the country joins EAC with deficit financing capped by convergence requirements. Averaging about 12.3 percent of GDP in the last 
five years (2010-2015), Uganda's tax to GDP ratio has grown by only 0.5 percentage points over this period, stagnating in the range of 11-13 percent of GDP. This tax revenue yield compares poorly with EAC countries and will have adverse implications for fiscal objectives under the EAC convergence criteria (Figure 9). In EAC, Uganda's tax to GDP ratio is the lowest. Indeed, Uganda's tax to GDP ratio over the period FY2008/09 to FY2015/16 averages 11.8 percent compared to Kenya, Rwanda and Tanzania that averaged 18.2 percent, 14.1 percent and 16.1 percent over the same period. A disaggregation of tax revenue as a percentage of GDP actually shows that across VAT, Income tax and Import duty Uganda performs lowest when compared to Kenya and Tanzania.

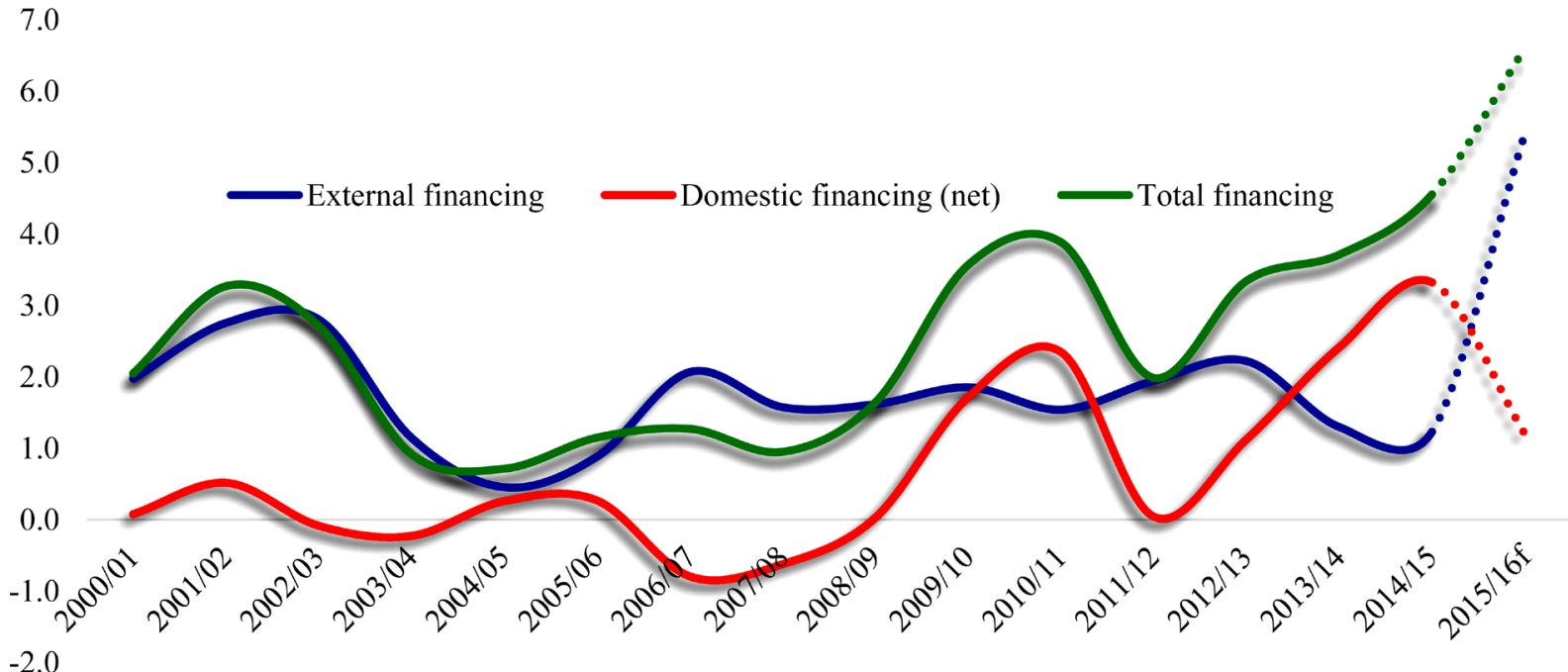

Source. Computed from Ministry of Finance data

Figure 8. Financing requirements, in percent of GDP.

25
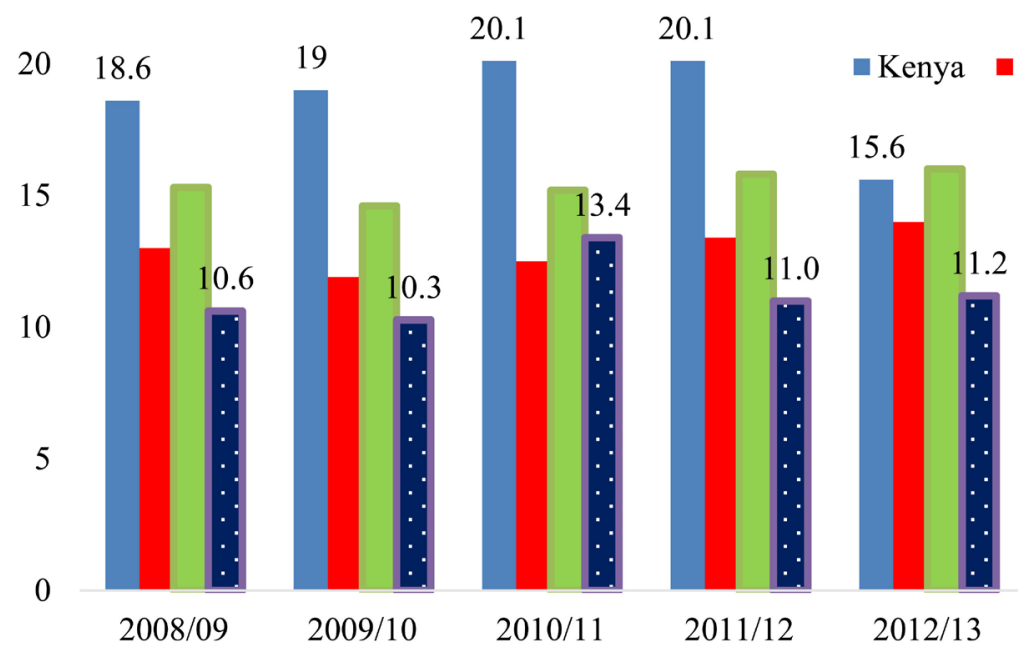

Source: IMF

$2011 / 12$

2012/13

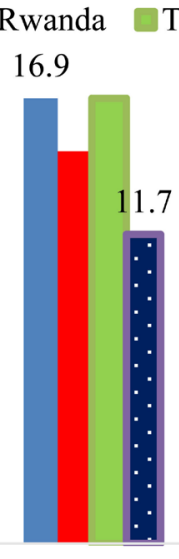

$\begin{array}{cr}17.6 & \text { Uganda } \\ 17.6\end{array}$
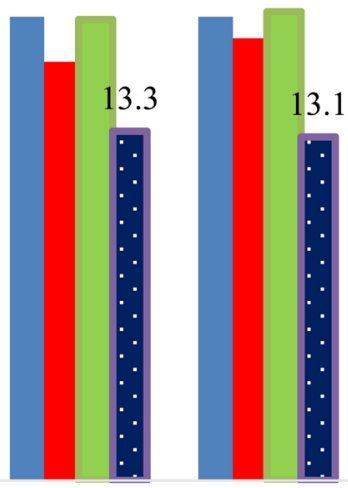

$2013 / 14$

$2014 / 15$

2015/16

Figure 9. Tax revenue, in percent of GDP. 
Uganda's low tax to GDP ratio is reflected in the sluggish growth in VAT and Income tax revenue (Figure 10). At an average (FY2008/09 to FY2015/16) of 4.1 percent of GDP, income tax yield in Uganda is much lower than Kenya's (8.9 percent) and Tanzania's (5.5 percent). Also, VAT yield is lower, at an average of 3.9 percent of GDP compared to Kenya (5.3 percent) and Tanzania (4.7 percent) in the corresponding period. The growth in these tax bases has been sluggish as yields have largely remained stagnant for the last five years. As such, efforts to boost Uganda's revenue yields and thus improve its fiscal space for the increased public investments ought to prioritize VAT and Income tax bases.

The poor performance of VAT revenue in Uganda is due to low collection efficiency and productivity. Uganda's VAT revenue productivity is low at 21.4 percent compared to Kenya (34.8 percent), Rwanda (33.9 percent), Tanzania (30 percent) and the sub Saharan Africa average of 33.7 percent (Figure 11). Furthermore, in terms Collection Efficiency ${ }^{1}$, Uganda's score at 28.6 percent is much lower than that of Kenya, Rwanda, SSA and Tanzania at 44.4, 41.7, 48.7

10.0

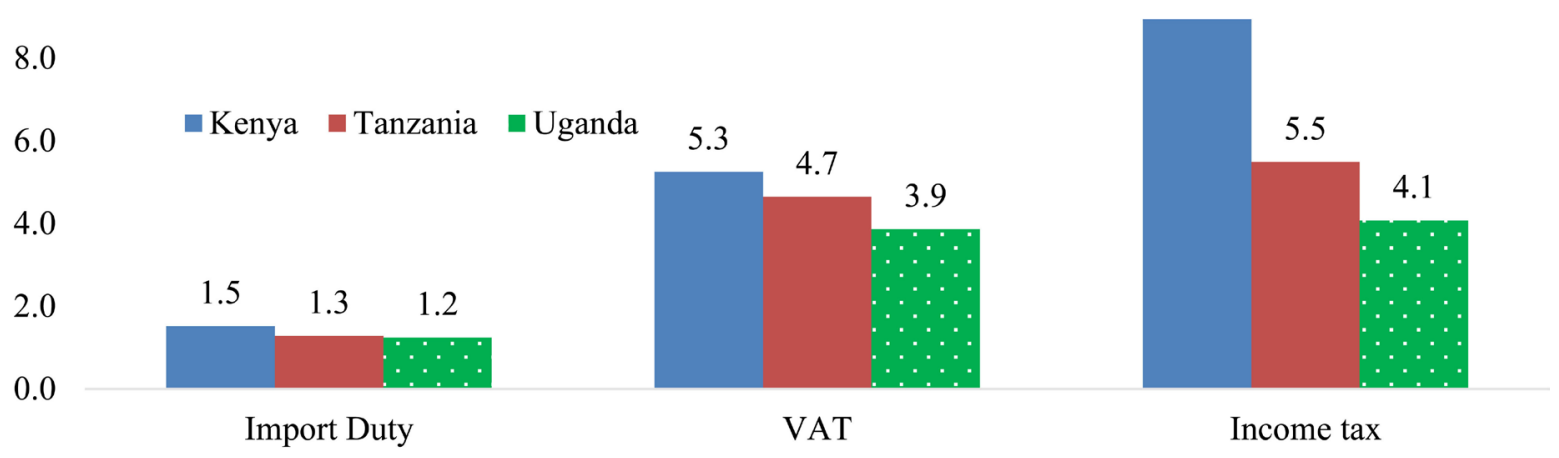

Source. IMF

Figure 10. Tax revenue (Average 2008/09-2015/16), in percent of GDP.

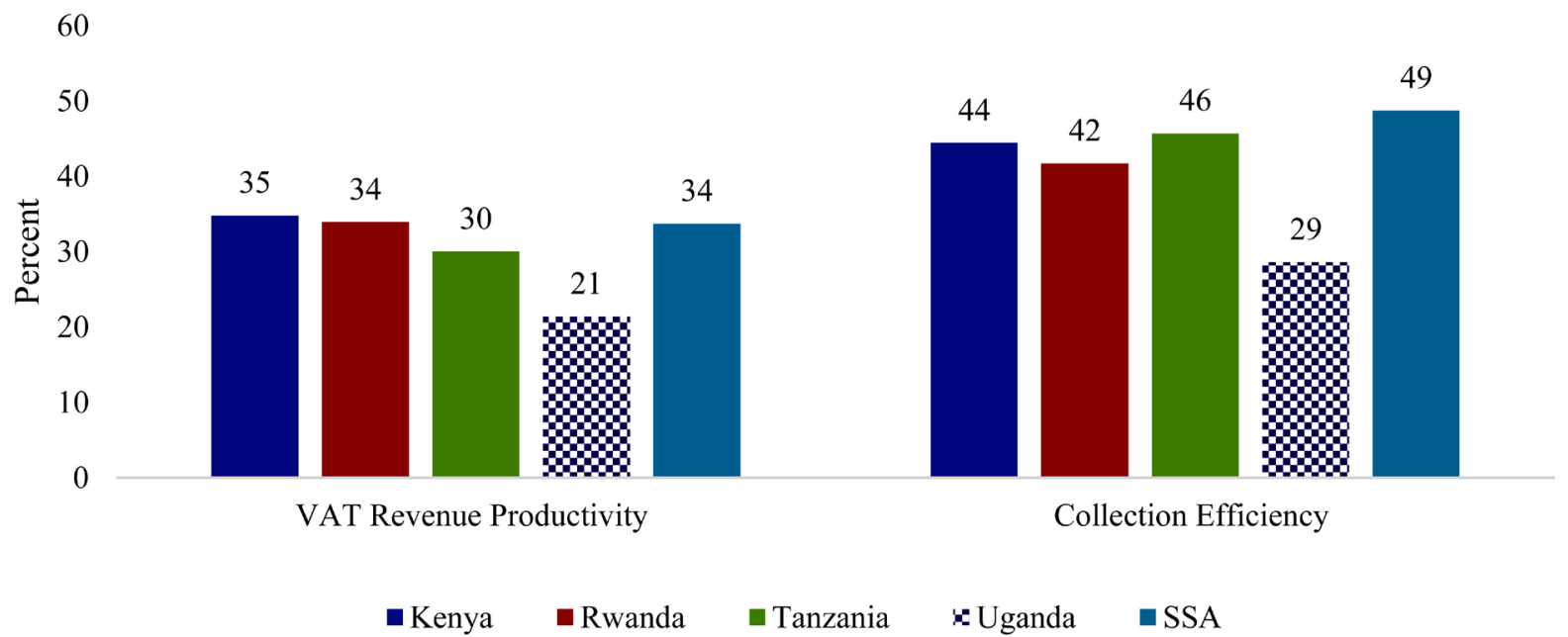

Source: Hutton et al (2014)

Figure 11. VAT revenue performance.

${ }^{1}$ Ratio of VAT revenue to the product of the standard rate and final consumption. 


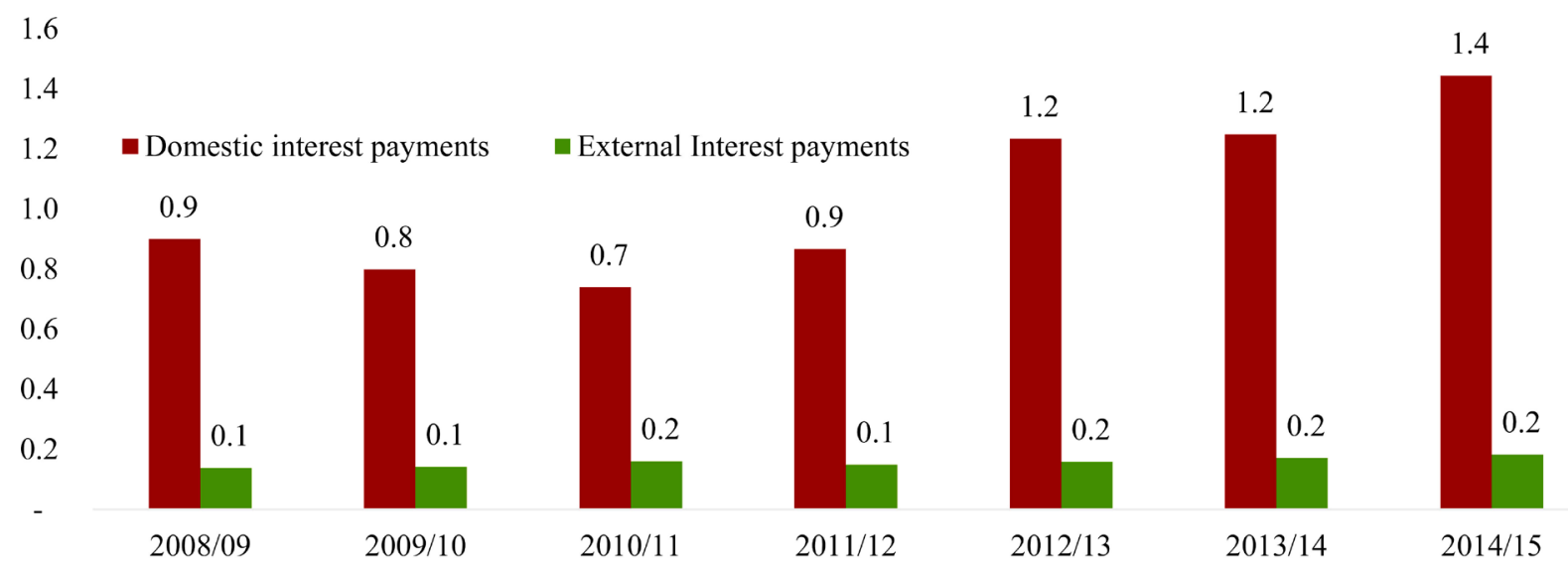

Source. Computed from Ministry of Finance data

Figure 12. Interest rate payments, in percentage of GDP.

and 45.7 percent respectively [16]. The 28.6 percent Collection Efficiency implies that 81.4 percent of potential VAT revenue is lost perhaps due to VAT exemptions, administrative inefficiencies, avoidance and evasion.

Government interest payments are on the steady rise. This is in line with Government's increasing deficit financing and stagnant tax revenue growth. Over the period FY2008/09 to FY2014/15, government interest payments have risen from 1 percent of GDP to 1.6 percent of GDP respectively and are expected to rise to 2.1 percent of GDP in 2015/16 (Figure 12). Prior to 2015/16, the increase in interest payments is largely attributed to increased use of short term domestic financing to finance government spending. Indeed, over the period FY2008/09 to FY2014/15, domestic interest payments averaged 1 percent of GDP while external interest payments average 0.2 percent of GDP.

\section{Analysis of Composition and Execution of Public Investments Plan (PIP) Budget}

Infrastructure sectors account for the largest share of the public investments budget and this share has increased in the recent years to reflect government's priorities as stipulated in the NDPs. Public Investments Plan (PIP) budget allocation to Infrastructure sectors (Works and Transport and Energy sectors) increased from 2.5 percent of GDP (average in 2004/05-2008/09 period) to 3.7 percent of GDP in the last six years (2009/10-2014/15). This represents an increase in the sector share of the PIP budget from 33 percent to 39 percent in the corresponding period (Figure 13). Infrastructure spending is directed to flagship projects in roads, electricity generation and oil and gas sectors identified in the NDP.

National security investments have also significantly increased in the recent years. Increasing regional security and terrorism concerns have necessitated increased public investments in the security sector. As such, PIP budget allocation to the sector increased from 0.1 percent of GDP (average in 2004/05-2008/09 period) to 0.5 percent (average in 2009/10-2014/15 period). 
While Education sector dominates overall social sector budget allocations, Health sector dominates the social sector PIP budget allocations. Second to infrastructure sectors, health sector takes a large share of the PIP budget. Nevertheless, the sector allocation has somewhat declined from 0.8 percent of GDP (average 2004/05-2008/09) to 0.6 percent in the last six years. Education sector PIP budget has caught up to Health sector PIP budget allocation as it increased by $0.2 \mathrm{pp}$ in the in the last six years.

Prioritization of the infrastructure sectors is also visible with donor financing of PIP projects and health sector dominates social sector donor allocations, albeit declining. At an average of 1.3 percent of GDP in FY2004/05-FY2014/15 period, the donor PIP budget allocation to Infrastructure sectors (Works and Transport and Energy sectors) dominates other sector allocations, however, this allocation has remained largely stagnant (Figure 14). Nevertheless, donor PIP

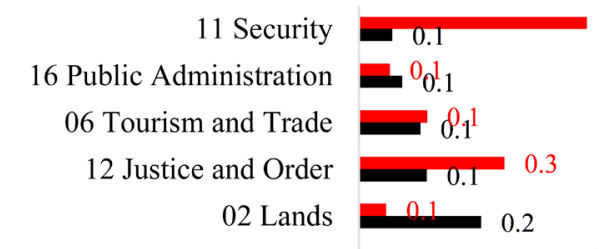

09 Water and Environment 0.3

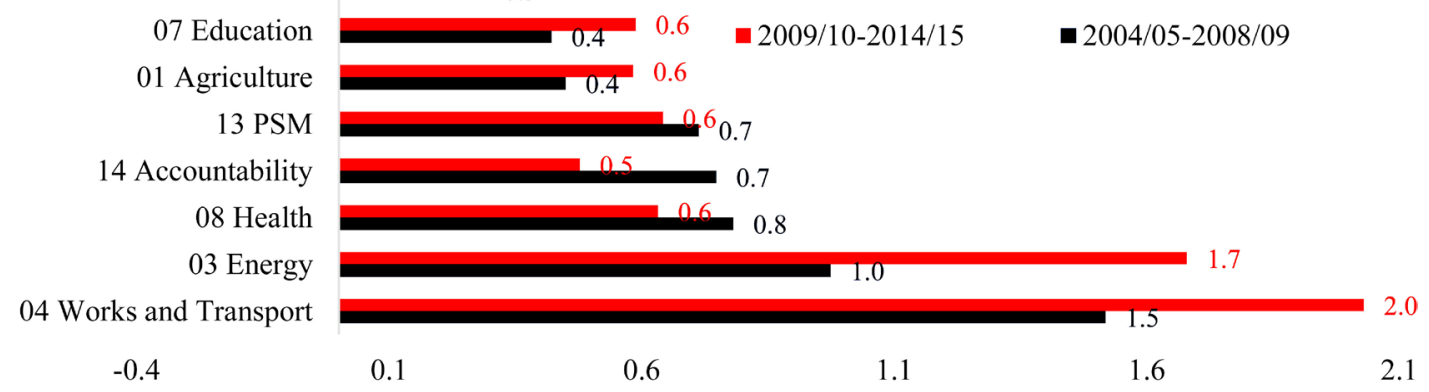

Source. Author Computations based on MoFPED data

Figure 13. Public Investments Project Budget Allocation, in percent of GDP.

06 Tourism and Trade

09 Water and Environment

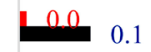

02 Lands

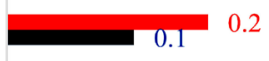

07 Education
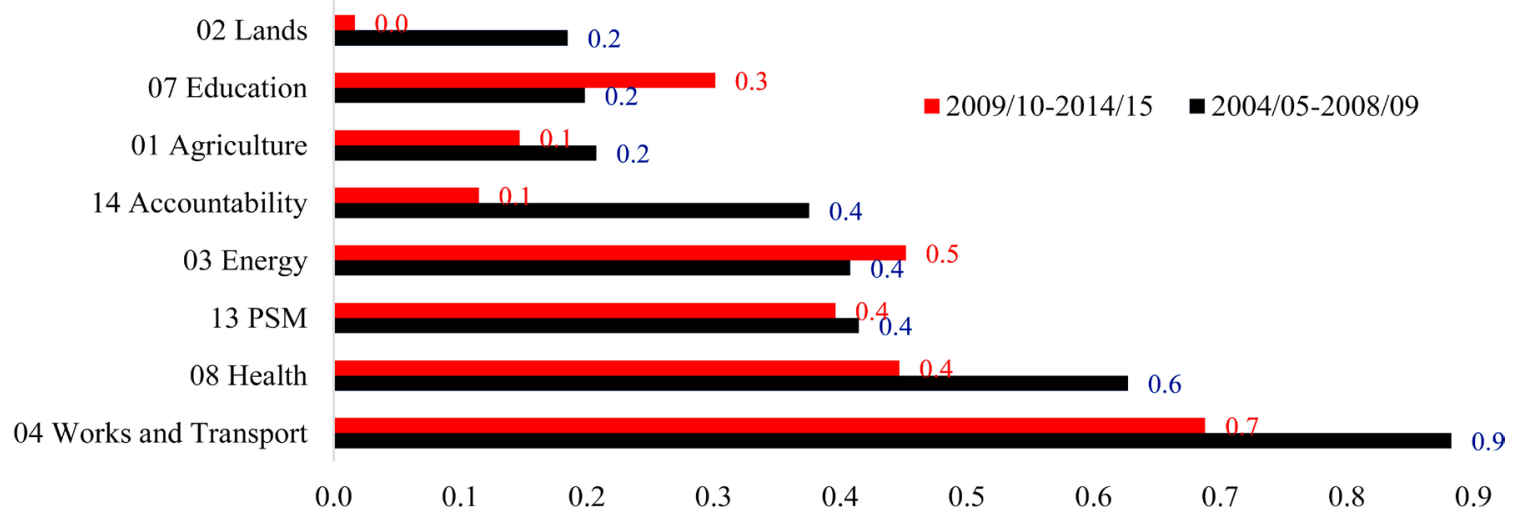

Source. Author Computations based on MoFPED data

Figure 14. PIP Donor Budget Allocations. 


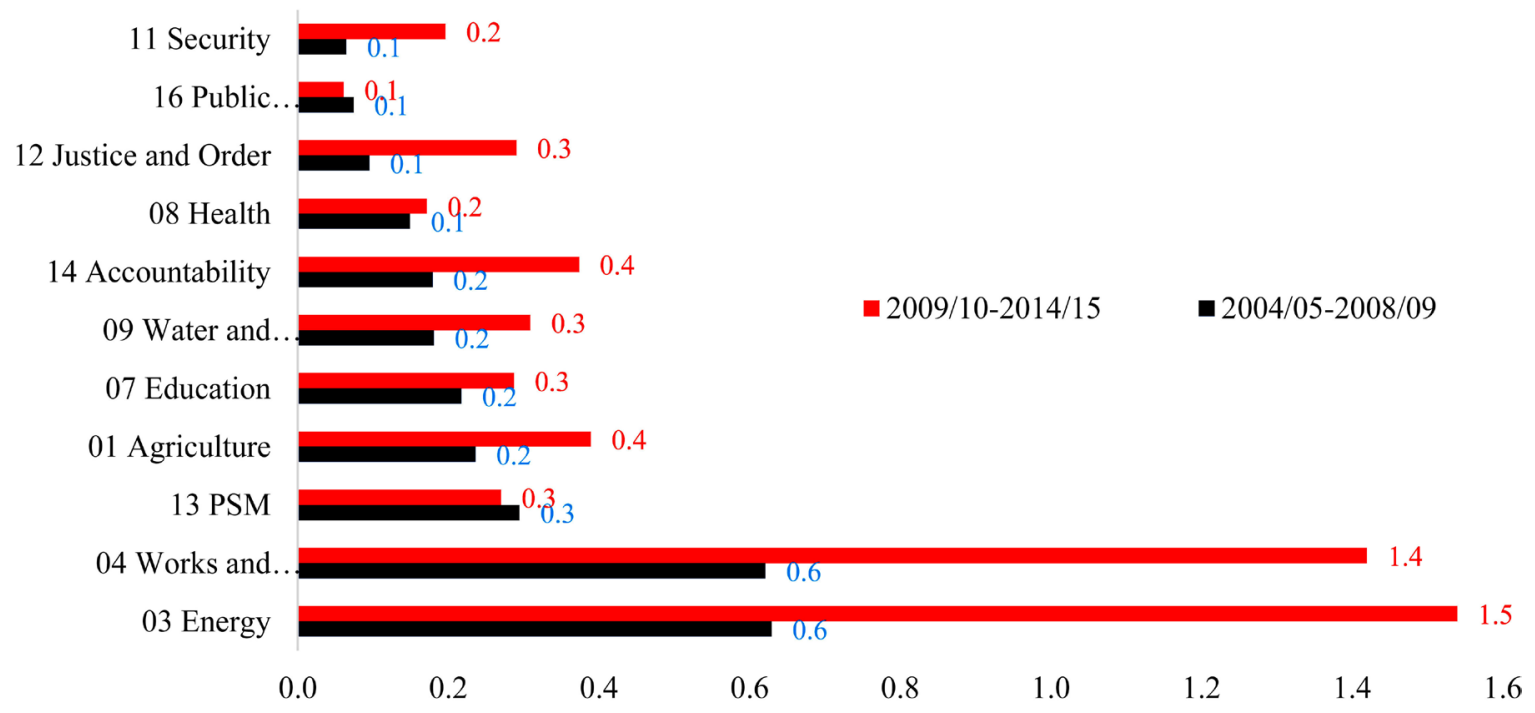

Source. Author Computations based on MoFPED data

Figure 15. PIP GoU Budget Allocation.

infrastructure budget allocation has shifted from the Works and Transport sector to Energy sector in recent years.

GoU has evidently prioritized infrastructure sectors in its PIP in recent years and social sector investments have largely been left to donors. The infrastructure PIP budget allocation has more than doubled from an average of 1.3 percent of GDP in 2004/05-2008/09 to 3 percent in the last six years (Figure 15). As such, in the past six years on average more than half (54 percent) of GoU PIP budget allocation has been allocated to infrastructure sector. Nevertheless, unlike donor PIP budget allocation agriculture prioritization emerges in GoU PIP budget allocation. Accountability and Justice, Law and Order sectors also emerge as GoU priorities as their PIP budgets increased in the last six years.

Government is increasingly using its own resources to finance public investments. Government financing of public investments has increased from an average of 3.5 percent of GDP (2004/05-2009/10) to 5.4 percent of GDP in the last six years (Figure 16). Conversely, donor financing (excluding non-concessional loans) has reduced from 3.4 percent of GDP to 2.9 percent in the corresponding period. The use of non-concessional financing (NCB) has increased particularly planned for FY2015/16. This NCB financing also increases government's autonomy over use of PIP resources in addition to own resources. The increased use of GoU's own resources and NCB for PIP has increased government's autonomy to select, appraise, manage and evaluate PIP projects has increased. As such, the success and efficiency of Uganda's public investments will depend on GoU's PIM capacity.

Despite the increasing independency in PIP financing, budget absorption has been a challenge especially for infrastructure sectors. Actual sector expenditure PIP allocations particularly for the infrastructure sectors fall below their budget allocations, indicating weak execution. Infrastructure sectors actual expenditure 


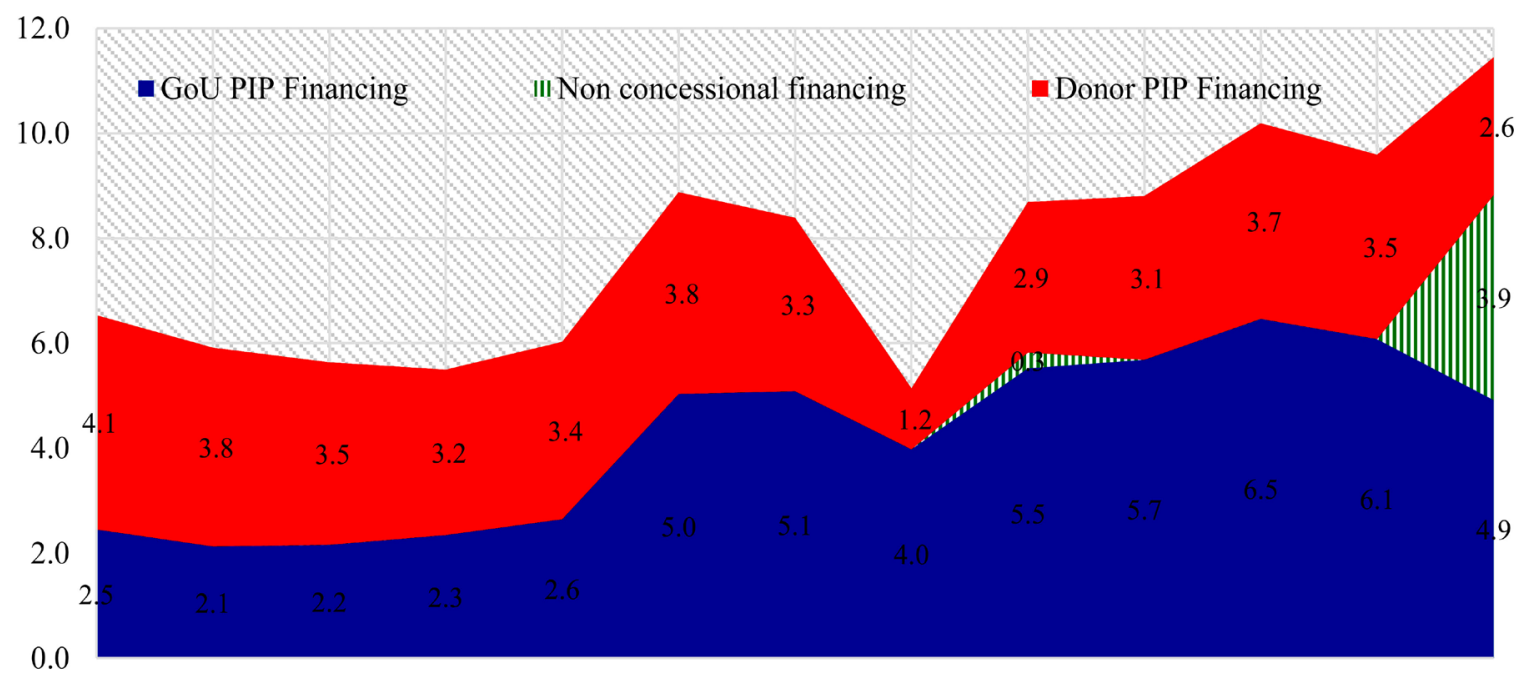

2003/04 2004/05 2005/06 2006/07 2007/08 2008/09 2009/10 2010/11 2011/12 2012/13 2013/14 2014/15 2015/16

Source. Author Computations based on MFPED data

Figure 16. Sources of PIP Financing.

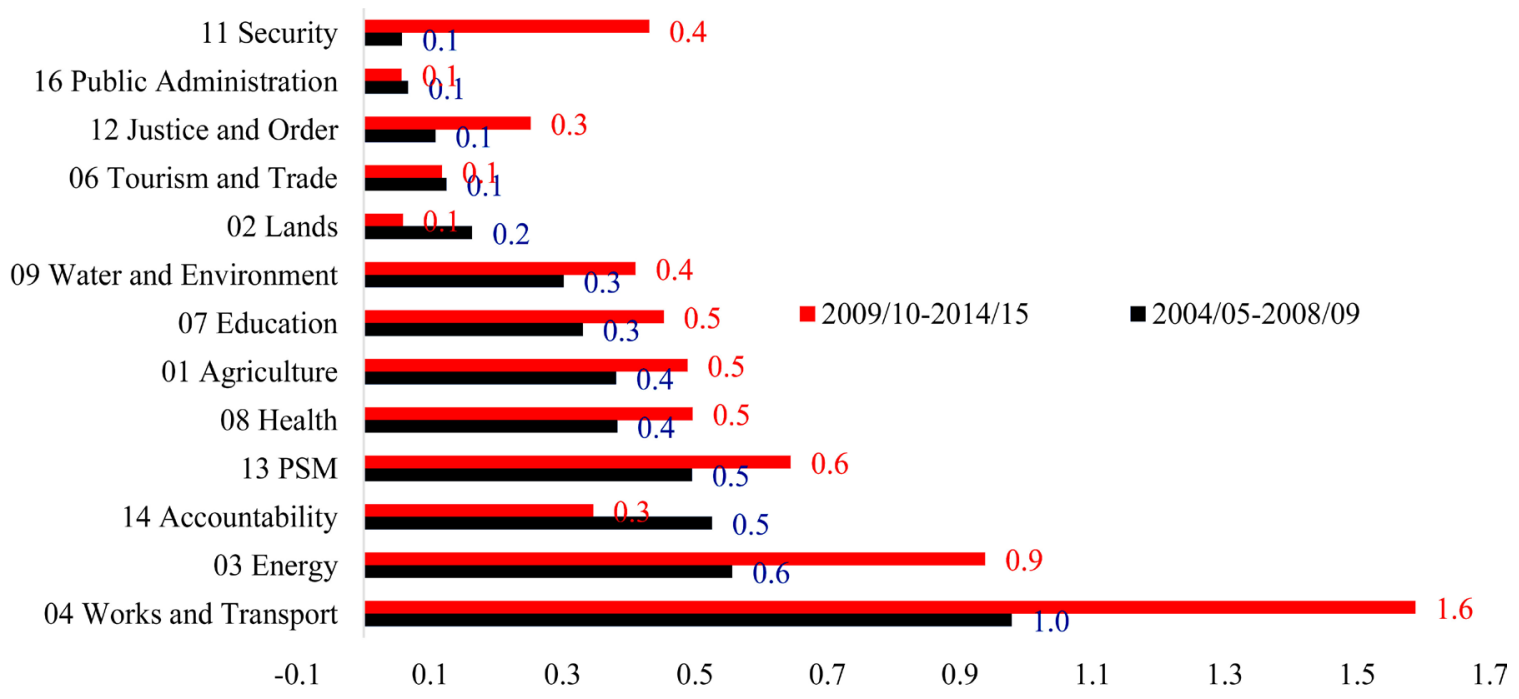

Source. Author Computations based on MoFPED data

Figure 17. PIP Actual Expenditure Allocation, in percent of GDP.

averaged 1 pp of GDP lower than planned in FY2004/05-FY2014/15 period (Figure 17).

At an average 74 percent in the last decade (FY2004/05-FY2014/15), overall PIP budget execution rate has been particularly poor; consistently constraining fiscal policy objectives set out in NDPs. Nevertheless, PIP budget execution has somewhat improved over the last six years from an average of 69 percent (in FY2004/05-FY2014/15 period) to 78 percent (Figure 18). This improvement in execution was largely due to improvements in the donor component of PIP which improved from a deviation of 54 percent to 20 percent in the corresponding period. On the contrary the GoU component execution deteriorated from 14 percent deviation against plans to 28 percent. With increasing importance of 


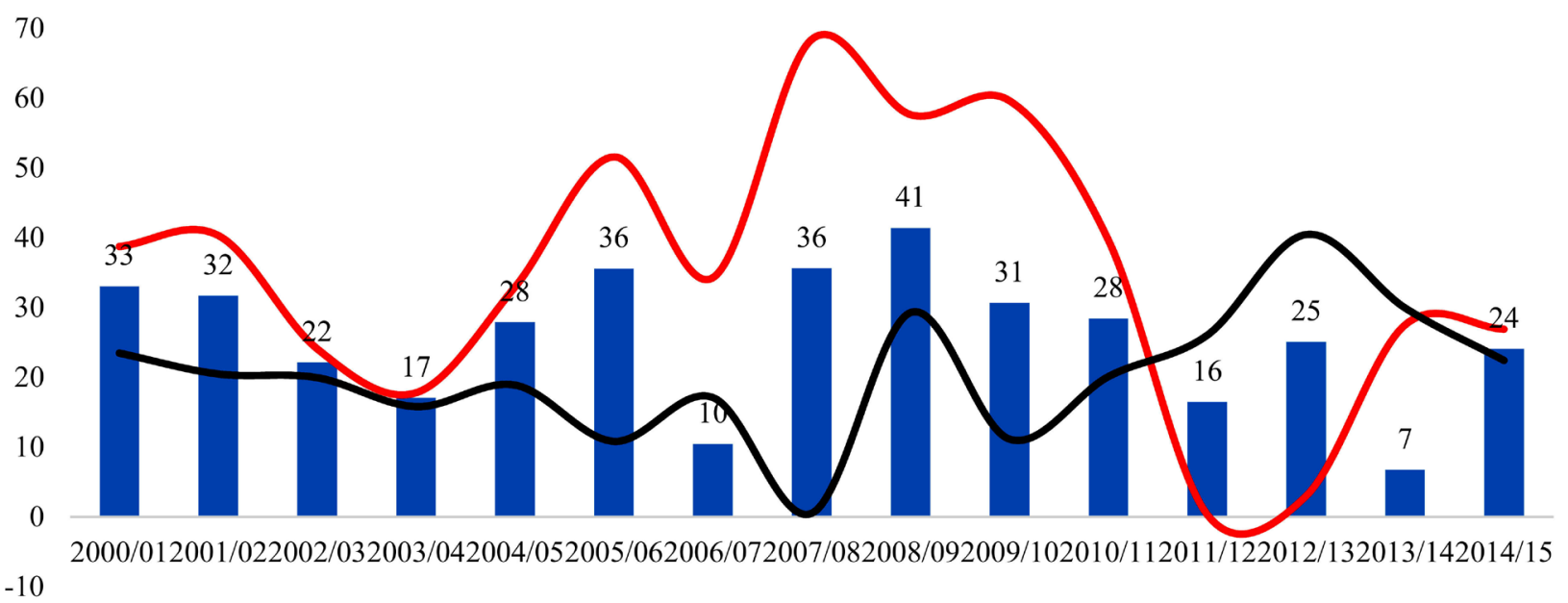

Overall PIP variance $\longrightarrow$ Donor variance $\longrightarrow$ GoU variance

Source. World Bank, Author Computations

Figure 18. PIP Actual/Budget Expenditure Variance (2000-15), in percent in absolute terms.

Sector PIP Budget Deviation against Actual Expenditure percent of GDP

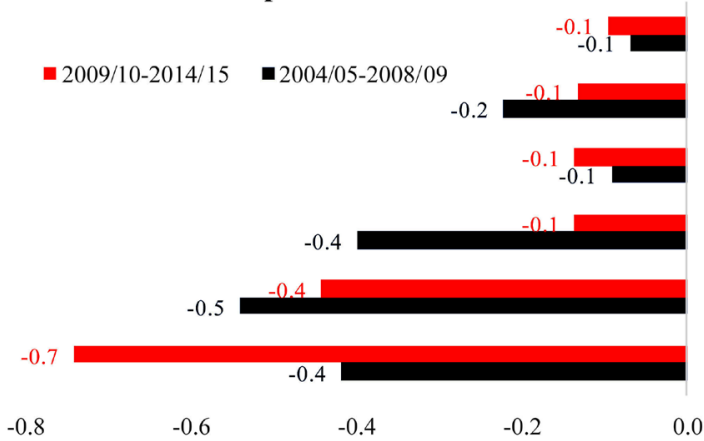

Source. AuthorComputations based on MFPED data
PIP Sector budget execution rate, in percent

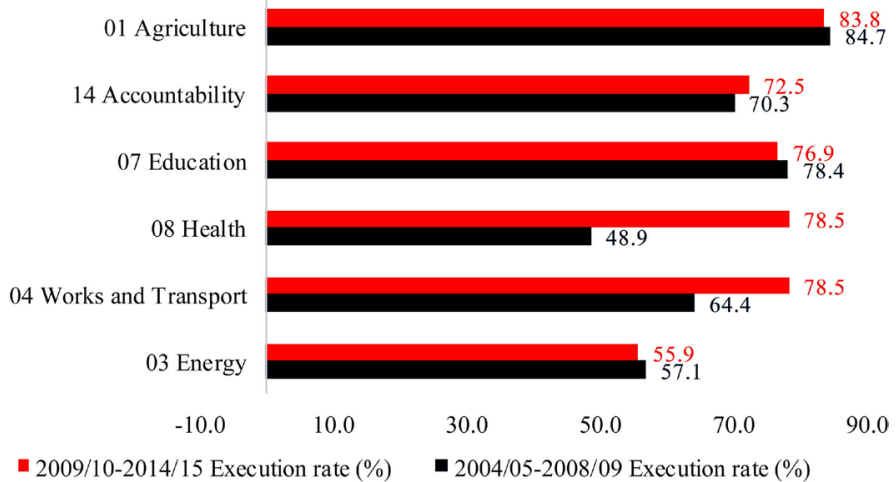

Figure 19. PIP Performance (Actual versus Budgeted).

GoU PIP component, it is critical that PIP budget execution is enhanced to improve the efficiency of public investment outlay.

Infrastructure sectors have particularly under executed their planned PIP budgets and this under execution has particularly increased in the energy sector.

Despite increasing Energy sector PIP budget allocation (Figure 19, left), public investment projects' execution has somewhat deteriorated in the sector from an average of 57.1 percent in FY2004/05-FY2008/09 period to 56 percent in the last six years (Figure 19, right). This has worsened the sector budget deviation from a short fall of 0.4 percent of GDP to 0.7 percent in the corresponding period. Further, while Transport sector has recorded some improvements in the execution rate, at an average of 79 percent execution rate in the last six years (FY2009/10-FY2014/15), the sector is still registering weak PIP execution. Over the last decade, the infrastructure sector (Energy and Transport sectors) contributed on average about 1 pp of GDP shortfall in PIP fiscal objectives. This weak 
execution points to PIM capacity gaps to select, prepare, budget, appraise, source financing and evaluate infrastructure projects. This has ramifications for overall GoU/NDP prioritization and frontloading of infrastructure projects. In that, in order to ensure efficiency of public investments that are necessary to unlock Uganda's economic potential, it is crucial to strengthen Uganda's PIM capacity.

\section{Discussion of Findings and Implications for PIM}

\subsection{Discussion of Findings from Fiscal Policy and Policy Implications for PIM}

Since 2009/10 Uganda's has been on an expansionary fiscal policy, driven by need for fiscal stimuli following the global down turn and the need to bridge a huge infrastructure deficit. This expansionary fiscal policy is driven by priority public infrastructure projects financed through deficit financing. This deficit financing stems from sluggish domestic revenue yields on one hand and need to maximize this type of financing before the EAC convergence criteria restrictions are enforced on the other hand. More recently, the source deficit financing has also changed, largely from conditional concessional external financing to commercial financing both domestic and foreign. These findings have five major implications for PIM, namely:

First, fiscal strategy prioritizes infrastructure spending implying that PIM capacity must be in tandem with increased resources for public investments. Weak capacity will lead to low outcomes starting with low absorption of public investment budget. This has been an area of weakness of Ugandan budgets [17].

Second, deficit financing for public investment implies that PIM has to be strengthened to ensure value for money and increased returns from investments. Deficit financing will drive up debt levels which have to be repaid, in the limit. This is only possible if the public investments accrued provide adequate returns to boost the economy, for the economy to generate capacity to repay back the debt. The challenge facing a country with high levels of debt and limited resources for investment, where every dollar allocated to investment must be made to count and contribute to economic growth (1). This has been an area of great concern in Uganda. Indeed, a key risk to Uganda's fiscal strategy relates to the potential for public investments to fail to yield the expected growth and welfare dividend if not managed effectively and efficiently. Over the past decade, for every dollar invested in the development of Uganda's capital infrastructure, only seven-tenth of a dollar has been generated (3).

Third, the changing nature of deficit financing from largely conditional and concessional long term debt to short-medium term commercial domestic and external debt has important implications for PIM in Uganda. The conditional, concessional long term debt that was provided mainly by World Bank and African Development Bank was accompanied by project management capacity. The projects were designed, implemented, and evaluated under the financing arrangements. Therefore, with a shift to commercial financing, the PIM capacity is 
solely dependent on Uganda's own capacity. As such, Uganda needs to urgently enhance its PIM capacity to bridge the capacity gap that has arisen due to change in deficit financing pattern. This will be crucial in ensuring that projects are well designed, implemented, managed so as to provide greater returns to the economy.

Further, the short-medium nature of financing is also a challenge for PIM. The projects designed must take cognizant of the available financing. The returns on the economy must accrue in the medium terms rather than later.

Fourth, Uganda's budget is largely executed at the Central Government (CG), implying that the PIM challenge is a CG issue. Therefore, while it is important to build PIM capacity across the general government, priority should be provided to CG projects executing departments. This will be crucial in improving efficiency and value for money in public investments projects.

Fifth, alternative financing must be sought to sustainably bridge Uganda's public infrastructure deficit. Deficit financing, particularly external commercial loans, cannot sustainably be relied on to bridge the infrastructure deficit. Indeed, the EAC convergence and macroeconomic sustainability restrictions will cap deficit financing in the medium term. As such, enhancing domestic resource mobilization at least to comparable EAC levels is one area that needs more strengthening. Uganda's tax yield is the lowest in the region mainly due to sluggish yields from VAT and income tax bases (16).

\subsection{Discussion of Findings from PIP Budget and Policy Implications for PIM}

Government independency in the selection and management of PIP projects has increased, implying the efficiency of public investments hinges on GoU's Public Investment Management (PIM) capacity. The bad news is that Government's capacity in Public Investment Management (PIM) is weak. While reducing dependence donor financing of public investments increases the necessity for government to have appropriate capacity to effectively manage projects this capacity is weak. This capacity was battered as donor capacity had swapped domestic capacity due to heavy reliance on donor financing of PIP.

Actual sector expenditure PIP allocations particularly for the infrastructure sectors fall below their budget allocations, indicating weak execution. Implying it is not lack of financing but it could be inadequate capacity to absorb the financing. The projects financed are not ready to go and this leads to resource wastage. This reduces the effectiveness of fiscal policy objectives and reduces the impact of budgeted infrastructure investments on the overall economy. Further, this consistent deviation in actual expenditure over budgeted spending points to weak execution capacity and weak PIM capacity in general.

A question arises what precedes what, is it financing or capacity to invest? To answer this question based on evidence provided is that Uganda needs to build adequate capacity to invest first before a fully blown financing strategy of its 
public investment projects. While financing of public investments should continue, these should be in tanderm with the available capacity to manage investments. As such, fiscal strategy that appropriately sequences Uganda's public investments in line with available absorption capacity is prudent and beneficial to a country such as Uganda.

\section{Conclusion}

The paper examines whether Uganda's fiscal strategy of availing resources for infrastructure investments indeed translated into planned expenditure on capital investments. The main question assessed is whether government was able to prudently absorb available resources to execute public investments. Low absorption capacity implies that it is not question of inadequate funds rather the inability to utilize the available funds. It is found that weak Public Investment capacity has led to less than budgeted public investment outturn which has reduced intended fiscal policy impact and diverted budgeted objectives. As such, for Uganda to achieve its development aspirations there is need to balance its expansionary fiscal policies with the ability to absorb fiscal resources. The study provides evidence for investing in capacity to invest before designing full blown expansionary fiscal policies aimed at boosting public investments so as to achieve intended fiscal policy objectives.

\section{References}

[1] Rajaran, A., Kaiser, K., Le, T.M., Kim, J.-H. and Frank, J. (2014) The Power of Public Investment: Transforming Resources into Assets for Growth. World Bank, Washington DC. https://doi.org/10.1596/978-1-4648-0316-1

[2] Smith, A. (1776) An Inquiry into the Nature of the Wealth of Nations. [trans.] Marxist.org. Random House, Inc., Oxford.

[3] World Bank (2016) From Smart Budgets to Smart Returns: Unleashing the Power of Public Investment Management. World Bank, Washington DC.

[4] Summers, L. (2017) Two Harvard Economists Debate Increased Infrastructure Investments. 18 January 2017, pp. 1-4.

[5] Mawejje, J. and Munyambonera, E. (2017) Financing Infrastructural Development in Uganda: Issues and Options. Economic Policy Research Centre, Kampala.

[6] Mawejje, J. (2013) The Business Climate in Uganda: Implications for Job Creation. Economic Policy Research Centre, Kampala.

[7] Calderon, C. and Serven, L. (2010) Infrastructure and Economic Development in sub-Saharan Africa. Journal of African Economies, 19, i13-i87. https://doi.org/10.1093/jae/ejp022

[8] National Planning Authority, NPA (2015) Second National Development Plan. Government of Uganda, Kampala.

[9] Glaeser, E. (2018) Two Harvard Economists Debate. 18 January 2017, pp. 1-4.

[10] Keynes, J.M. (1936) The General Theory of Employment, Interest, and Money. Harcourt, Bracer, New York.

[11] Arrow, K.J. and Kurz, M. (1970) Public Investment, the Rate of Return and Optimal Fiscal Policy. John Hopkins Press, Baltimore. 
[12] Aschauer, D.A. (1989) Is Public Expenditure Productive? Journal of Monetary Economics, 23, 177-200. https://doi.org/10.1016/0304-3932(89)90047-0

[13] Glomm, G. and Ravikumar, D. (1997) Productive Government Expenditures and Long-Run Growth. Journal of Economic Dynamics and Control, 21, 183-204. https://doi.org/10.1016/0165-1889(95)00929-9

[14] Rodrigue, J.P. (2009) Geography of Transport Systems. 2nd Edition. Routledge, London.

[15] Easterly, W., Irwin, T. and Serven, L. (2008) Walking up the Down Escalator: Public Investment and Fiscal Stability. World Bank Research Observer, 23, 37-56.

[16] Hutton, E., Thackray, M.W. and Kapoor, K. (2014) Revenue Administration Gap Analysis Program-The Value-Added Tax Gap. International Monetary Fund, Washington DC.

[17] Ministry of Finance, Planning and Economic Development (n.d.) Background to the Budget. Ministry of Finance, Planning and Economic Development, Kampala. 